Check for updates

Cite this: Mater. Adv., 2020, 1, 3243

Received 7th October 2020, Accepted 9th October 2020

DOI: 10.1039/d0ma00772b

rsc.li/materials-advances

\title{
Overview of sterilization methods for UHMWPE through surface analysis $\dagger$
}

\author{
Melissa Machado Rodrigues, (D) *a Estela K. Kerstner Baldin, ${ }^{\text {ab }}$ \\ Cristian Padilha Fontoura, (D)*a Leonardo Mathias Leidens, (D) a \\ Rodrigo Antônio Barbieri, ${ }^{c}$ Rafaele Frassini, ${ }^{d}$ Célia de Fraga Malfatti, ${ }^{b}$ \\ Mariana Roesch-Ely, ${ }^{d}$ Carlos Alejandro Figueroa (D) $^{a}$ and Cesar Aguzzoli (D)
}

\begin{abstract}
The sterilization process is essential for the use of biomaterials in the human body in order to avoid contamination. However, the effect of such required pretreatment on the surface must be also evaluated since some modifications may cause a shortened lifespan of this material or changes in properties of interest. Moreover, improvements in sterilization techniques may even enhance properties while the surface is cleaned. The thorough understanding of the effect that the sterilization processes have on the surface of ultra-high molecular weight polyethylene (UHMWPE), widely used biomaterial in orthopedic joint prosthesis, is, therefore, a key study since some modifications during traditional sterilization could be a major problem for patients who have undergone arthroplasty surgery. This work brings a comprehensive study on sterilization techniques already available and extensively used (hydrogen peroxide plasma, ethylene oxide, steam autoclave) and a comparison with results obtained for recently developed cold plasma-based sterilization technique. The effects of the processes have been extensively compiled by data obtained for thermal analysis, nanoscale wear and friction, physicochemical, topographical, wettability, and in vitro cytotoxicity experiments. An overall outlook on the set of samples points out to cold plasma oxidation (CPO) being an adequate and potential candidate for improving wear resistance, while maintaining thermal stability and a restrained adhesion of L929 cells, provoked by its hydrophilicity and larger surface area.
\end{abstract}

\section{Introduction}

Ultra-high molecular weight polyethylene (UHMWPE) is the most used biomaterial in orthopedic joint prosthesis, with its use dating back to the $1960 \mathrm{~s}^{,{ }^{1-3}}$ UHMWPE has a semicrystalline structure, with around half of polymeric chains organized in the

\footnotetext{
${ }^{a}$ Área do Conhecimento de Ciências Exatas e Engenharias, PPGMAT,

Universidade de Caxias do Sul, Caxias do Sul, RS 95070-560, Brazil. E-mail: cpfontoura@ucs.br,melissa1807@gmail.com

${ }^{b}$ Laboratório de Pesquisa em Corrosão (LAPEC), Universidade Federal do Rio Grande do Sul (UFRGS), Porto Alegre 9500, RS 91501-970, Brazil

${ }^{c}$ Laboratório Central de Microscopia - LCMIC, Universidade de Caxias do Sul, Caxias do Sul, RS 95070-560, Brazil

${ }^{d}$ Instituto de Biotecnologia, Universidade de Caxias do Sul, Caxias do Sul, RS 95070-560, Brazil

$\dagger$ Electronic supplementary information (ESI) available: Fig. A1: Diffraction patterns used for the estimation of crystallinity on the set of samples. Fig. A2: High resolution scanning electron microscopy images of the CPO samples after 1, 2 and 7 days of incubation. Fig. A3: High resolution scanning electron microscopy images of the EtO samples after 1, 2 and 7 days of incubation. Fig. A4: High resolution scanning electron microscopy images of the HPP samples after 1, 2 and 7 days of incubation. Fig. A5: High resolution scanning electron microscopy images of the SA samples after 1, 2 and 7 days of incubation. See DOI: 10.1039/ d0ma00772b
}

form of crystalline lamellae and the other half in a crosslinked amorphous phase. ${ }^{4}$

This feature is occasioned by its glass transition temperature $T_{\mathrm{g}}=-80{ }^{\circ} \mathrm{C}$ and melting point $T_{\text {melt }}=135{ }^{\circ} \mathrm{C}$, both of which allow the unique viscosity. Furthermore, the amorphous behavior allows other ideal properties for biomedical use, such as chemical inertness, low friction coefficient and a low wear rate. $^{2,4,5}$ However, sterilization processes are mandatory, in order to eliminate microbial life before implantation. ${ }^{2,6}$

Nowadays, there are several methods for sterilizing such materials such as ethylene oxide (EtO), ${ }^{6}$ hydrogen peroxide plasma (HPP), steam autoclave (SA) and cold plasma oxidation (CPO) reflecting the lack of scientific consensus over which of the methods is best suiting, considering long-term effects on patients. ${ }^{7,8}$

Autoclave sterilization is one of the most commons techniques that ensure complete decontamination in a fast, economical and reliable way. It consists of pressurized chamber with water vapor and programmed cycles that go up to a temperature of $134^{\circ} \mathrm{C}$ and a controlled time. Polymers are, however, thermosensitive to such techniques and polymeric chains may degrade by hydrolysis or lose stability during asepsis cycles, compromising application in joint arthroplasty. ${ }^{6}$ 
Another technique being employed for over five decades to neutralize bacteria, viruses and spores in heat-sensitive products is ethylene oxide (EtO). ${ }^{7,9}$ This process occurs by the gaseous diffusion of a mixture of ethylene oxide and carbon dioxide or other inert compounds near the surface of parts, through a certain period of time. This happens usually within a few hours and its efficiency depends on conditions such as humidity, time and temperature. ${ }^{7,10}$ Polymers with a low melting point can be sterilized through this technique as long as an aeration is carried out afterwards, from 12 to 24 hours, to guarantee a complete release of residual gas. ${ }^{6,10}$ This additional aeration procedure is necessary, as EtO releases undesirable toxic waste. ${ }^{10,11}$ Also, unwanted physicochemical modifications may take place. ${ }^{6}$ It is also reported that EtO is mutagenic and carcinogenic and, therefore, is a risk to human health. ${ }^{10,11}$ EtO also requires high safety standards and high cost, restricting its use in most common lab facilities. ${ }^{12}$

A popular alternative is a low temperature plasma process. This method has been employed in UHMWPE since the 1990s and consists of sample exposition to reactive species generated by gas ionization, which will allow pathogen elimination. ${ }^{13,14}$ Plasma is generated by a radiofrequency (RF) source that provides a stable glow discharge, with biocide effects attributed to the ultraviolet radiation from it. ${ }^{14-16}$ In this process, plasma is considered the complementary detoxifying agent of the main agent - like hydrogen peroxide (HPP) or another gas mixture of them (CPO). ${ }^{13}$ Plasma sterilization is fast and guarantees no toxicity. ${ }^{11,13,17,18}$ A drawback, however, is how selective plasmainduced modification happens in semicrystalline materials: etching happens at a higher rate in amorphous regions, thus increasing surface crystallinity. ${ }^{19,20}$

In the last 10 years, a great number of failure reports involving polymeric pieces in arthroplasty applications have been published. ${ }^{10,21,22}$ The main factor behind this is described as oxidative degradation of the material, induced by sterilization processes. $^{22-25}$ Overall, sterilization processes remain a major problem when it comes to the use of polymeric materials in biomedical applications, since the employed energy induces rapid aging, oxidation and other surface phenomena that lead to materials fragilization. In practice, this means that a recipient of a load bearing polymeric part may be subjected to implant mechanical failure or problems with the formation of debris that accumulate around the tibial, patellar and acetabular components, causing bone inflammation and degradation. Oxidative degradation also influences wear and shortening the life span of the implanted UHMWPE. ${ }^{9}$

Therefore, four different sterilization techniques were used in UHMWPE samples and characterized in terms of their physicochemical, mechanical and biological properties. The results obtained were compared, with the purpose of verifying which of these processes is the most adequate to provide a complete material sterilization, without harming the physicalchemical and mechanical characteristics of the sterilized material. The sterilization techniques applied in this study were hydrogen peroxide plasma (HPP), ethylene oxide (EtO), steam autoclave (SA) and cold plasma oxidation (CPO).

\section{Materials and methods}

\subsection{Sample preparation}

The samples used in this work were obtained from a $6.9 \mathrm{~mm}$ thick UHMWPE plate (Braskem, Brazil). They were cut into $1.75 \mathrm{~mm} \times 1.75 \mathrm{~mm}$ and cleaned in ultrasonic bath - containing 10 minutes in Extran (MA 02, liquid neutral, $50 \mathrm{~g} \mathrm{~L}^{-1}$ in $\mathrm{H}_{2} \mathrm{O}-$ Supelco) and 20 minutes in distilled water. UHMWPE samples without sterilization treatment were called "pristine".

\subsection{Sterilization processes}

Sterilization processes used in UHMWPE are described, along with their acronyms, as follows: cold plasma oxidation (CPO); ethylene oxide (EtO); hydrogen peroxide plasma (HPP) and steam autoclave (SA). Table 1 gives a description of all procedures used in the different sterilization processes performed.

Hereafter, UHMWPE samples sterilized by different processes were named as follows: pristine (UHMWPE without sterilization), CPO (UHMWPE sterile cold plasma oxidation); EtO (UHMWPE sterile ethylene oxide); HPP (UHMWPE sterile hydrogen peroxide plasma) and SA (UHMWPE sterile steam autoclave).

\subsection{UHMWPE characterization before and after sterilization processes}

The samples in pristine form, CPO, EtO, HPP and SA were characterized for their physicochemical, thermal, mechanical and biological properties.

Table 1 Description of sterilization procedures used

\begin{tabular}{|c|c|c|}
\hline Process & $\begin{array}{l}\text { Place where sterilization } \\
\text { was performed }\end{array}$ & Sterilization protocol \\
\hline $\mathrm{CPO}^{26}$ & $\begin{array}{l}\text { LESTT, Universidade } \\
\text { de Caxias do Sul - UCS } \\
\text { (Caxias do Sul, Brazil) }\end{array}$ & $\begin{array}{l}\text { The plasma configuration used was hollow cathode with } 13.56 \mathrm{MHz} \text { radiofrequency power source (for } \\
\text { plasma generation), } 1 \mathrm{mbar} \text { (working pressure), } 27 \mathrm{~W} \text { power, } 20 \% \text { volume oxygen content, hydrogen } \\
\text { content by volume of } 80 \% \text { within } 15 \text { min in room temperature. }\end{array}$ \\
\hline $\mathrm{EtO}^{27}$ & $\begin{array}{l}\text { Company } \mathrm{A}^{a} \\
\text { (Caxias do Sul, Brazil) }\end{array}$ & $\begin{array}{l}\text { Pressure of } 0.65 \text { atm, at temperature of } 55{ }^{\circ} \mathrm{C} \text {, for } 180 \text { minutes with gas (Chemogas) composed of } 90 \% \\
\text { ethylene oxide and } 10 \% \text { carbon dioxide. }\end{array}$ \\
\hline $\mathrm{HPP}^{27}$ & $\begin{array}{l}\text { Company } \mathrm{B}^{a} \\
\text { (Caxias do Sul, Brazil) }\end{array}$ & $\begin{array}{l}\text { A Sterrad NX sterilizer (Johnson and Johnson) was used for a period of } 28 \text { minutes. Temperature during the } \\
\text { sterilization cycle ranged from } 45^{\circ} \mathrm{C} \text { to } 55^{\circ} \mathrm{C} \text {. ANVISA certified parameters. }\end{array}$ \\
\hline $\mathrm{SA}^{27}$ & $\begin{array}{l}\text { Company } \mathrm{A}^{a} \\
\text { (Caxias do Sul, Brazil) }\end{array}$ & $\begin{array}{l}\text { Autoclave used is the Baumer brand, } 050500001 \text { series, horizontal model HI-VAC Plus, with a capacity of } \\
0.56 \mathrm{~m}^{3} \text {. The conditions used were as follows: temperature of } 134{ }^{\circ} \mathrm{C} \text {; pressure of } 0.70 \text { atm; and } 7 \text { minutes } \\
\text { of exposure. }\end{array}$ \\
\hline
\end{tabular}

${ }^{a}$ Company A and B are institutions specialized in sterilization processes. Their names are protected for commercial reasons. 
2.3.1. Contact angles (WCA). Measurements were taken at room temperature using a tensiometer (SEO Phoenix 300, South Korea) by the sessile drop method with distilled water as fluid. The measurements were made in different regions of the sample surface and an average of 6 measurements was calculated.

2.3.2. Profilometry. Stylus profilometer (Model Talysurf Intra 50 equipped with a standard stylus 112/2009, Taylor Hobson, UK) was used to evaluate the roughness of the samples. An average of 3 trails $(5 \mathrm{~mm})$ was performed in different directions on the surface of the samples.

2.3.3. Attenuated total reflectance by Fourier transform infrared spectroscopy (ATR-FTIR). ATR-FTIR was used to obtain infrared spectra in attenuated total reflectance mode. The spectra were recorded in the range of $4000 \mathrm{~cm}^{-1}$ to $400 \mathrm{~cm}^{-1}$ in a spectrophotometer (400, PerkinElmer, USA) in order to observe any changes in functional groups of the polymer.

2.3.4. FEG-SEM. A field emission scanning electron microscopy equipment (FEG-SEM, Tescan MIRA3, Czech Republic) was used in high vacuum mode with the maximum beam voltage of $15 \mathrm{kV}$ to evaluate the topography and cell adhesion in the CPO sample (gold-coated in sputtering equipment) after 1, 2 and 7 days of incubation time. This same technique was also applied to identify the trails obtained in different samples after nanoscratch tests.

2.3.5. SEM. The scanning electron microscopy equipment (SEM, Shimadzu, SSX-550, Japan) was used to evaluate cell adhesion in the EtO, HPP and SA samples after 1, 2 and 7 days of incubation. The samples were gold-coated in sputtering equipment and examined with a SEM in high vacuum mode with the maximum beam voltage of $15 \mathrm{kV}$.

2.3.6. X-ray diffraction. X-ray diffraction (XRD) was used to verify the change in sample crystallinity after different sterilization treatments. The diffraction patterns were obtained between $5^{\circ}-50^{\circ}$ using a Bragg-Brentano diffractometer (Model $\mathrm{XRD}-6000$, Shimadzu, Japan), with $\mathrm{Cu}-\mathrm{K} \alpha$ radiation of $\lambda=$ 1.5406 A through $\theta / 2 \theta$ mode. After obtaining the diffractograms it was possible to calculate the degree of crystallinity of the samples.

The values of degree of crystallinity were estimated by the method of fitting the areas of crystalline peaks and amorphous phases, followed by the calculation of the ratio between crystalline and amorphous portions. This was carried out with the aid of the native software of the equipment used for the obtention of diffraction patterns.

2.3.7. Thermal gravimetric analysis (TGA). By TGA analysis it was possible to verify the effect that the different sterilization methods have on the thermal stability of the materials under study. About $10 \mathrm{mg}$ of sample was used for this assay and measurements were made under nitrogen atmosphere $\left(20 \mathrm{~mL} \mathrm{~min}^{-1}\right)$ with a heating rate of $10{ }^{\circ} \mathrm{C} \min ^{-1}$ until reaching $600{ }^{\circ} \mathrm{C}$. A Shimadzu (Japan) - Model TGA-50 thermobalance was used.

2.3.8. Differential scanning calorimetry (DSC). The DSC analyzes were performed in a device (Shimadzu DSC-50, Japan) under nitrogen atmosphere $\left(20 \mathrm{~mL} \mathrm{~min}^{-1}\right)$ with two heating cycles. In the first cycle, the samples were heated to $200{ }^{\circ} \mathrm{C}$ $\left(10{ }^{\circ} \mathrm{C} \mathrm{min}^{-1}\right)$, where they were kept under isothermal conditions for $3 \mathrm{~min}$. In the second cycle, the samples were cooled to $20{ }^{\circ} \mathrm{C}$. With the obtained results, it was possible to determine the melting temperature $\left(T_{\mathrm{m}}\right)$ and to evaluate the changes in the crystallization behavior of the samples treated by different sterilization processes. Eqn (1) was used to obtain the degree of crystallinity of the different samples and to compare them, following the ASTM F2625-10 standard. ${ }^{28}$

$$
X(\%)=\frac{\Delta H_{\mathrm{f}}}{\Delta H_{\mathrm{f}}^{\circ}} \times 100 \%
$$

where $\Delta H_{\mathrm{f}}$ is the heat fusion of the composites obtained from DSC and $\Delta H_{\mathrm{f}}^{\circ}$ is the fusion enthalpy of $100 \%$ crystalline polymer $\left(\Delta H_{\mathrm{f}}^{\circ}=289 \mathrm{~J} \mathrm{~g}^{-1}\right.$ for UHMWPE).

2.3.9. Nanoscratch. Unidirectional sliding tests were used to assess the microwear behavior of UHMWPE with different surface treatments (sterilizations) using a conical diamond tip with radius of $25 \mu \mathrm{m}$ in a NanoTest-600 nanotribometer (MicroMaterials, UK). The procedure was the same to all the set of samples: a normal load of $0.01 \mathrm{mN}$ was applied in the first $100 \mu \mathrm{m}$ of scanning and then it was increased at a rate of $0.1 \mathrm{mN} \mathrm{s}^{-1}$ until reaching the pre-determined normal load (50 $\mathrm{mN}$ ). The maximum load was maintained during the last $50 \mu \mathrm{m}$. The total distance of each scratch was $\sim 650 \mu \mathrm{m}$ (with a constant sliding velocity of $1 \mu \mathrm{m} \mathrm{s}^{-1}$ ) and all the samples were submitted to at least five repetitions. The temperature was fixed at $(25 \pm 1){ }^{\circ} \mathrm{C}$ with a relative humidity of $(55 \pm 2) \%$ in a closed chamber. After the experiments, the surfaces were evaluated by means of FEG-SEM.

2.3.10. Atomic force microscopy (AFM) and lateral force microscopy (LFM). An atomic force microscope (SPM-9700 Shimadzu, Japan - LFM mode) equipped with a silicon tip (ending radius of $<10 \mathrm{~nm}$ ) mounted on rectangular shaped cantilever (PPP-LFMR - Nanosensors) and nominal spring constant of $\sim 0.2 \mathrm{~N} \mathrm{~m}^{-1}$ was used to evaluate surface roughness and topography (AFM) and friction forces at the nanoscale (LFM). Temperature and relative humidity were kept constant at $(18 \pm 2){ }^{\circ} \mathrm{C}$ and $(60 \pm 2) \%$, respectively, during the experiments. In order to analyze quantitatively the friction, the tip was previously calibrated with a well-stablished method. ${ }^{29}$ Both topographical and friction force images $(2 \mu \mathrm{m} \times 2 \mu \mathrm{m}$ and resolution of $512 \times 512$ pixels) were obtained at a scan rate of $1.0 \mathrm{~Hz}$ and normal force of $\sim 5.0 \mathrm{nN}$ (contact mode). Raw data was analyzed and refined using an open-source software (Gwyddion) available at http://gwyddion.net/..$^{30}$

\subsection{UHMWPE biological characterization before and after sterilization processes}

The samples were characterized for their biological behavior. The purpose of this study was to verify the effect that different sterilization treatments performed on the surface of UHMWPE have on cytotoxicity and cell adhesion.

2.4.1. Exposition of UHMWPE samples to cell medium. The extract solution was prepared according to the standard ISO 10993-5-2009-2. The CPO, EtO, HPP and SA samples $\left(3 \mathrm{~cm}^{2} \mathrm{~mL}^{-1}\right)$ were immersed in Dulbecco's Modified Eagle's medium (DMEM) 
(Sigma-Aldrich ${ }^{\circledR}$ ), supplemented with $10 \%$ fetal bovine serum (Gibco BRL; Life Technologies) and 1\% penicillin-streptomycin (Sigma-Aldrich ${ }^{\circledR}$ ), in a humidified $5 \% \mathrm{CO}_{2}$ atmosphere at $37{ }^{\circ} \mathrm{C}$. Then, four different extraction solutions were obtained, one for each sterilization method.

2.4.2. Cell viability. Cell viability was evaluated by MTT [3-(4,5-dimethylthiazol-2-yl)-2,5-diphenyltetrazolium bromide] assay and performed according to ISO 10993-5 (2009) and ISO 10993-12 (2004) protocols. The fibroblast cell line L929 from mouse lung connective tissue was seeded in 96-well plates at a density of $1 \times 10^{5}$ cells $\mathrm{mL}^{-1}$. After $24 \mathrm{~h}$ incubation, the cells were treated with four separately extracts solutions of polyethylene during 1, 2 and 7 days, respectively. DMEM culture medium supplemented with $10 \%$ fetal bovine serum and $1 \%$ penicillin/streptomycin was used for negative control and 5\% dimethylsulfoxide (DMSO) for positive control. After the period of each treatment, the culture medium was removed and the MTT solution ( $0.4 \mathrm{mg} \mathrm{mL} \mathrm{m}^{-1}$ ) was added for an incubation time of 2 hours. After removing the MTT, formazan crystals were solubilized in DMSO. The optical density (OD) was performed on a microplate reader (Spectramax2xe, Molecular Devices, USA) at $570 \mathrm{~nm}$. The cell viability rate (\%) was calculated as follows: (OD of the treated group/OD control group) $\times 100$.

2.4.3. Morphological analysis. The cell line L929 was seeded directly on the CPO, EtO, HPP and SA samples at the same density as described above, for 1, 2 and 7 days, respectively. Cells were then fixed with $3 \%$ glutaraldehyde solution in PBS (v/v) for $15 \mathrm{~min}$, with subsequent dehydration with 30, 50, 70, 90 and $100 \%$ (v/v) ethanol for $10 \mathrm{~min}$. After, the samples were kept in a desiccator until the analysis was performed.

\section{Results and discussion}

The present section exhibits the results and following insight on data for the studied sterilization methods. A correlation of the outcomes with existing literature was made to provide an overview of the processes.

\subsection{Surface wettability (WCA)}

Surface wettability is an important property to be studied in biomaterials it that directly influences biocompatibility, growth and cell adhesion. ${ }^{31,32}$ In case of UHMWPE used as a substitute for joint cartilage, the hydrophilic characteristic is essential for a good interaction with bone cells, ${ }^{32}$ with surface modification being often employed. ${ }^{31,33,34}$ Table 2 shows the calculated average of the WCA results obtained in the pristine, CPO, EtO, HPP and SA samples as well as the standard deviation values.

One can observe, in Table 2, that all the sterilization treatments performed at UHMWPE altered the surface wettability when compared to the sample without any treatment (pristine). All sterile samples presented values of WCA between $72^{\circ}$ and $88^{\circ}$, indicating hydrophilicity characteristics (WCA $<90^{\circ}$ ) which is opposite to the $102^{\circ}$ result of the pristine sample, agreeing with preceding results. ${ }^{26,35}$ In particular, an investigation ${ }^{31}$ studied the changes that occurred on the surface of the UHMWPE after the plasma-assisted microwave Electron Cyclotron Resonance (ECR) and the effect that these changes cause in relation to the interaction with bone cells. The results obtained indicated the change of the hydrophobic surface (UHMWPE without treatment) to hydrophilic (after treatment). In addition, the author proves in his experiments that UHMWPE with hydrophilic characteristics has a better adhesion of bone cells. ${ }^{31}$ In Section 3.9, further explanation will be presented regarding the effect that the WCA results have on the cell adhesion test.

\subsection{Surface roughness}

Surface roughness is a major criterion for assessing biomaterials in terms of biocompatibility, due to their ability of providing a prediction model for cellular and bacterial adhesion. ${ }^{1,2,7}$ Many works have correlated this property with cell adhesion and biocompatibility, with no universal consensus yet achieved; rather, materials are individually considered depending on their class, surface energy, and application. ${ }^{36-38}$

In this work, the average roughness $\left(R_{\mathrm{a}}\right)$ of the samples sterilized by different techniques was measured by stylus profilometry and AFM. The results and standard deviation obtained are shown in Fig. 1, where the three-dimensional profiles acquired by AFM are also displayed. The results presented indicate that the UHMWPE surface is highly susceptible to topography modification after carrying out the different sterilization processes, since the results of the average roughness obtained $\left(R_{\mathrm{a}}\right)$ showed significant changes when compared to pristine. The sample sterilized by ethylene oxide (EtO) was the one that showed roughness results close to that of the pristine sample. More pronounced microgrooves are visible in CPO samples, which indicates a stronger plastic deformation as consequence of plasma ion bombardment effects of etching and cross-linking. ${ }^{39}$

According to a study that investigated the effect of surface roughness on cell growth and adhesion, ${ }^{40}$ an increase in cell

Table 2 Contact angles for samples treated with different sterilization processes compared to pristine

Contact angle $\left(^{\circ}\right)$

\begin{tabular}{|c|c|c|c|c|}
\hline Pristine & CPO & EtO & HPP & SA \\
\hline
\end{tabular}



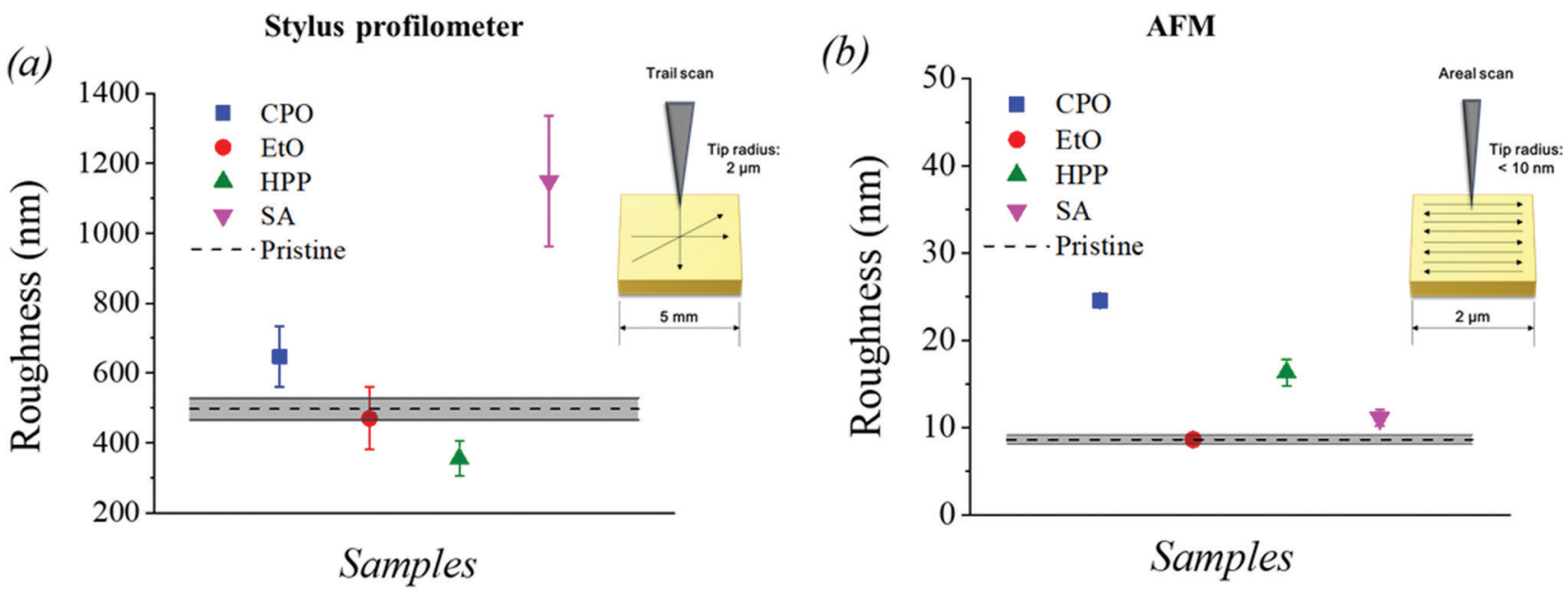

(c)
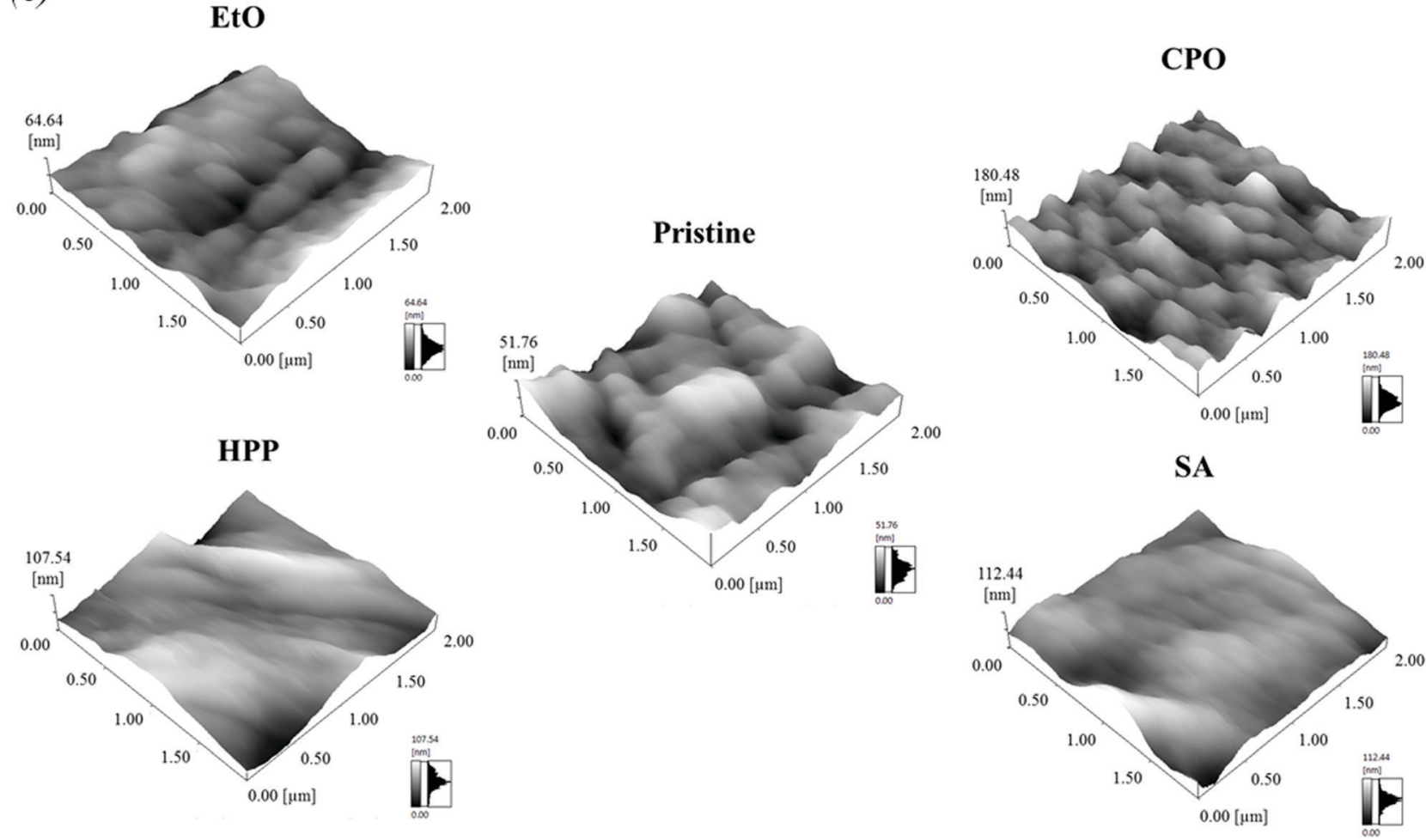

Fig. 1 Roughness $\left(R_{\mathrm{a}}\right)$ obtained by stylus profilometry (a) and AFM (b). Shaded regions represent standard deviation for pristine condition, with a continuous line. 3D profiles obtained by AFM are also displayed (c).

growth is perceived on the roughest surfaces. However, this increase in cell growth was observed in all rough samples, regardless of the $R_{\mathrm{a}}$ obtained. A more specific approach on this point will be discussed in Section 3.9 of this paper.

\subsection{ATR-FTIR}

To determine the effect that different sterilization treatments have on the surface of the UHMWPE, in terms of functional groups, FTIR spectroscopy analysis was performed. As the treatments can affect only a few nm below the UHMWPE surface, FTIR spectroscopy was evaluated in ATR mode. The vibrational spectra obtained from the pristine sample and samples sterilized by different treatments were normalized and can be seen in Fig. 2a. Fig. 2b highlights two regions of interest for the functional oxidation groups.

Fig. 2a shows some very intense and characteristic absorption peaks of the UHMWPE at 721, 1482, 2846 and $2913 \mathrm{~cm}^{-1}$ which correspond, respectively, to the vibration in the plane of the $-\mathrm{CH}_{2}$ connection, flexion vibration $-\mathrm{CH}_{2}$, symmetrical elongation $-\mathrm{CH}_{2}$ and non-symmetric stretching vibration $-\mathrm{CH}_{2} \cdot{ }^{18,31}$

With the regions of the spectra highlighted (Fig. 2b), it is possible to observe, in details, where the functional oxidation groups appear. The absorption band in $3360 \mathrm{~cm}^{-1}$, which refers 
(a)

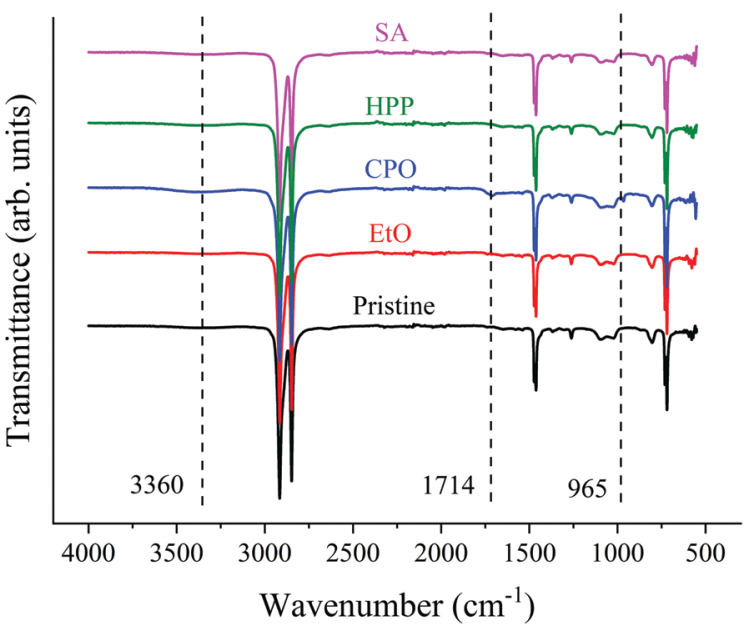

(b)

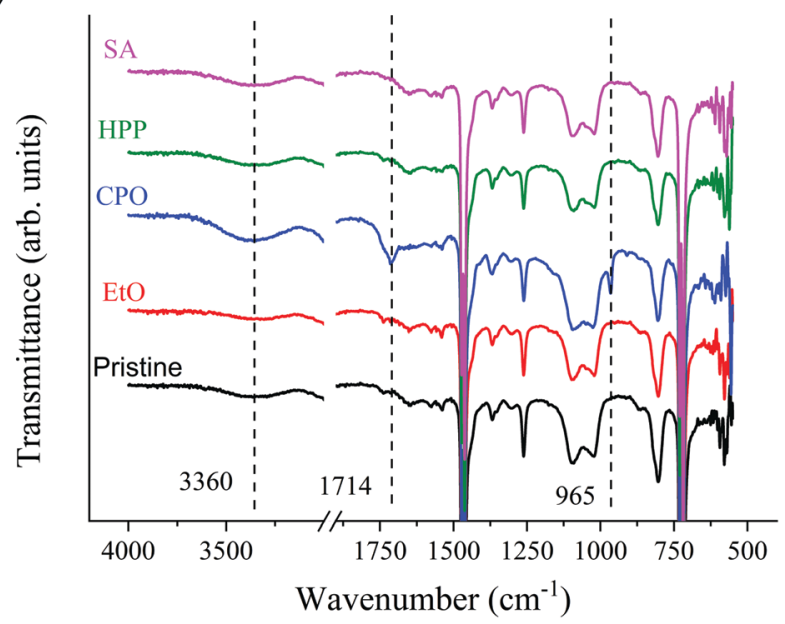

Fig. 2 (a) ATR-FTIR spectra for the set of samples and (b) ATR-FTIR spectra normalized of the samples.

to $\mathrm{OH}$ is observed for $\mathrm{CPO} .{ }^{32}$ When comparing the spectra for the different conditions, no other significant modification on surface functional groups is observed, ${ }^{6}$ apart from CPO sample. A distinctive peak for $\mathrm{C}=\mathrm{C}$ around $965 \mathrm{~cm}^{-1}$ could be observed for CPO sample, which is attributed to trans-vinylene unsaturation, due to ionization that leads to detachment of hydrogen molecule. The transmittance or absorbance perceived in ATR-FTIR spectra for this peak is linearly proportional to dose level. ${ }^{9,17}$ Also, transvinylene declines at very high oxidation levels, indicating that, probably, this is an unoxidized or mildly oxidized UHMWPE. ${ }^{11}$ The peak for $\mathrm{C}=\mathrm{O}$ stretching at the band $1714 \mathrm{~cm}^{-1}$ indicates oxidation, which is high on surface level, but decays gradually into the sample's core ${ }^{3,23}$ and has been associated with plasma treated UHMWPE. ${ }^{4}$ Although the CPO sample showed oxidation bands, they were not intense enough to harm the bulk sample, as can be seen in the presented TGA and nanoscratch results.

\subsection{Crystallinity analysis}

UHMWPE is a semicrystalline material, composed of a combination of amorphous and crystalline phases - the crystalline phase is made of chains folded into oriented lamellae and crystals displaying orthorhombic structure. In a previous work, ${ }^{41}$ an exhaustive revision of UHMWPE structure and mechanical performance is discussed. One of the hypotheses raised, concerning its crystallinity, tells us that changes in amorphous regions, conveyed from increase in temperature (during the sterilization processes), will have a negative effect on mechanical properties ${ }^{14,24,42}$ being correlated to oxidation in retrieved implants. ${ }^{43}$ Also, fatigue strength has been associated with higher crystallinity, being lamellar thickness a parameter for such behavior. ${ }^{41,44,45}$ Increased surface crystallinity has also been linked to a decrease in friction responses at both microscale and nanoscale, along with increase in scratch and wear resistance. ${ }^{46}$

Sterilization methods studied in our work have been vastly used in clinical applications, therefore, the evaluation of the crystallinity of UHMWPE after performing the sterilization processes is essential to check if there has been a change in its structure that may have a negative effect on its mechanical properties.

DSC and XRD analyses deliver an understanding on the degree of crystallinity of semicrystalline samples, despite the fact that results for crystallinity degree are mismatched between the two techniques - once DSC is a dynamic measurement (over a temperature profile) and XRD is measured with a constant temperature. Fig. 3 presents the DSC curves for the set of samples with three cycles (heating, cooling and heating cycles, respectively). A few parallels can be remarked from the curves and are summarized in Table 3: the DSC results showed an increase in crystallinity for all sterilization methods, which means that the heating provided by the DSC technique influences the phase reduction amorphous form of UHMWPE and consequently in increasing its crystalline phase. ${ }^{47,48}$ Similar values for pristine condition are available in the literature. ${ }^{47,49}$

For XRD, the results for all but one (SA) of the methods displayed a very proximate degree of crystallinity. The diffraction patterns can be viewed in ESI $\dagger$ as Fig. A1. However, the sample treated by SA exhibited a crystallinity index that stands out from the others. It is known that high-pressure processes carried out at elevated temperatures contribute to increase in crystallinity of UHMWPE, ${ }^{50}$ but this was not the case for SA samples, which showed a marked decrease in crystallinity, in relation to the other samples. A major disadvantage of XRD measurements is how the results are influenced by the topography, which means that a variable roughness can fool the analysis of the diffraction peak, inducing more errors.

\subsection{Thermal analysis}

Thermal analysis (Fig. 5) was performed to investigate the oxidative stability of the material after the sterilization processes. If there is a chemical change (such as a change in the crystalline structure of the material) after the sterilization processes and which may affect the material's stability, it is possible to verify these changes by analyzing the resistance of the sample to forced oxidation. 

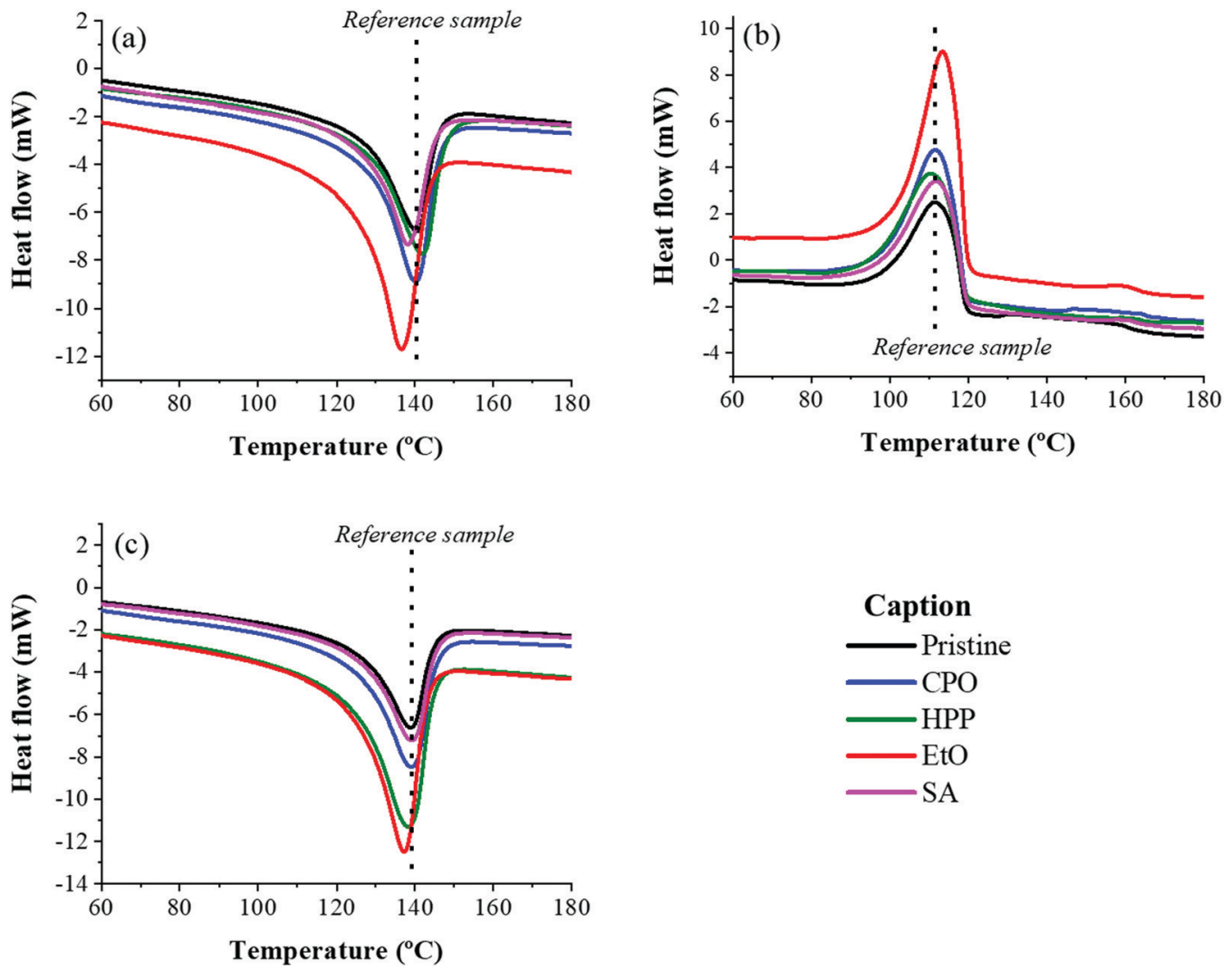

Fig. 3 DSC curves for the three cycles (a) first heating cycle, (b) cooling cycle and (c) second heating cycle for the set of samples.

Table 3 DSC analysis results, with: $T_{\mathrm{g}}=$ glass transition temperature, $T_{\mathrm{m}}=$ melting point, $\%=$ degree of crystallinity

\begin{tabular}{lllcc}
\hline Sample & $\begin{array}{l}T_{\mathrm{g}} \\
\left({ }^{\circ} \mathrm{C}\right)\end{array}$ & $\begin{array}{l}T_{\mathrm{m}} \\
\left({ }^{\circ} \mathrm{C}\right)\end{array}$ & $\begin{array}{l}\text { \% } X \text {, first } \\
\text { heating cycle }\end{array}$ & $\begin{array}{l}\% X, \text { second } \\
\text { heating cycle }\end{array}$ \\
\hline Pristine & 111.39 & 140.50 & 33.65 & 32.87 \\
CPO & 111.58 & 141.78 & 44.42 & 42.02 \\
EtO & 113.42 & 136.57 & 51.58 & 53.63 \\
HPP & 110.34 & 140.13 & 39.17 & 52.35 \\
SA & 111.74 & 138.08 & 35.60 & 36.41
\end{tabular}

TGA is a suitable characterization of oxidative stability in UHMWPE, ${ }^{51}$ being widely used in recent studies, ${ }^{52,53}$ serving here as a way to compare the sterilization processes with pristine conditions in terms of their thermal stability. According to the results presented in Fig. 5, the degradation behavior of the samples (percentage of mass loss) is observed when subjected to temperature increase. The onset of thermal degradation does not vary significantly among curves, attesting that the presence of $\mathrm{C}-\mathrm{O}$ or $\mathrm{C}=\mathrm{O}$ groups was limited. ${ }^{54}$ Mass loss rates were higher for all sterilized samples compared to the counterpart virgin condition, indicating slightly less thermally stable bulk for the set of samples. Over this analysis, CPO presented a similar stability compared to the pristine sample. It is worth mentioning that the CPO sample showed oxidation bands in the analysis of ATR-FTIR, while also displaying the greatest stability in relation to the material's original condition. The presented results confirm that the process of sterilization

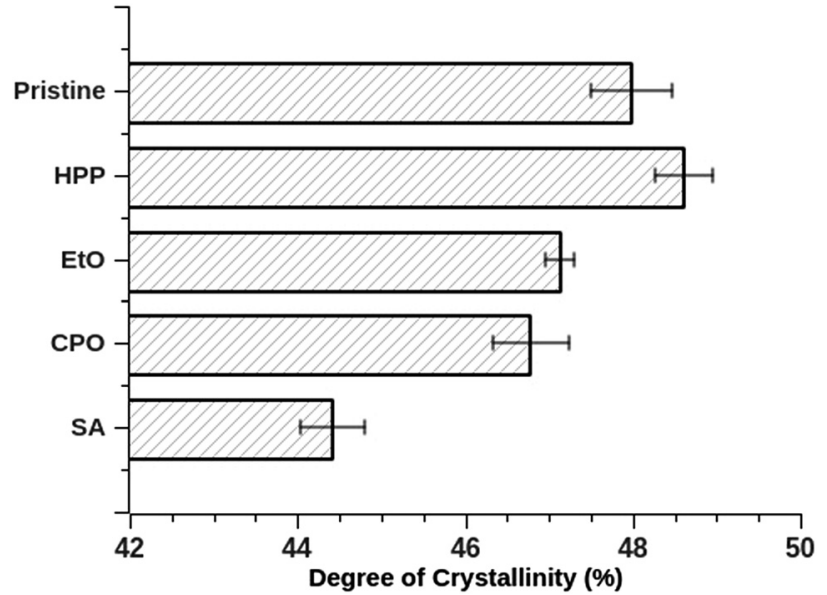

Fig. 4 Degree of crystallinity obtained through XRD for different samples.

by CPO oxidizes the sample just superficially, without damaging its bulk properties. Conversely, HPP presented a more divergent curve, meaning an intense splitting in the chain. This same condition showed a small increase in its crystallinity (Fig. 4), which is in line with the response obtained in the TGA thermograms.

\subsection{Nano-scratch}

Fig. 6a-e show the nanoscratch behavior of pristine, EtO, CPO, HPP, and SA samples, respectively, where the friction force is 

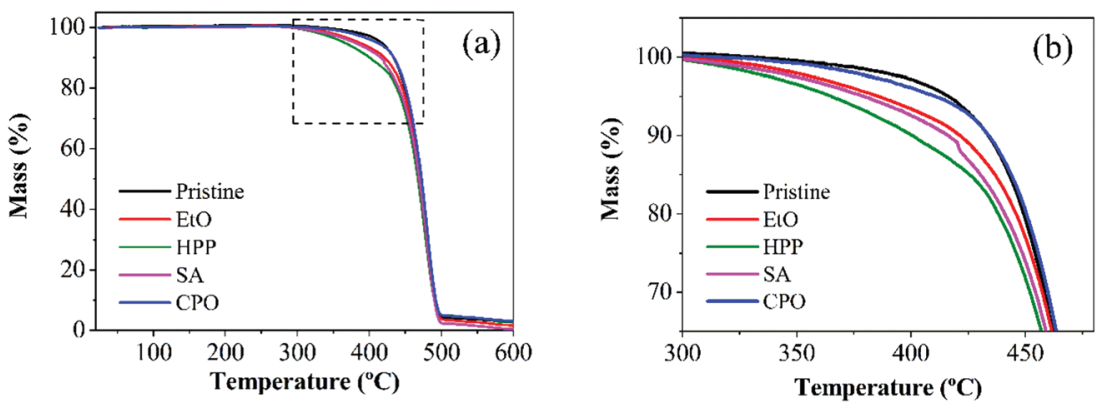

Fig. 5 TGA thermograms for the set of samples (a) from initial mass to its full degradation and (b) the threshold for the diverging mass loss rates, amplified from inset in (a).
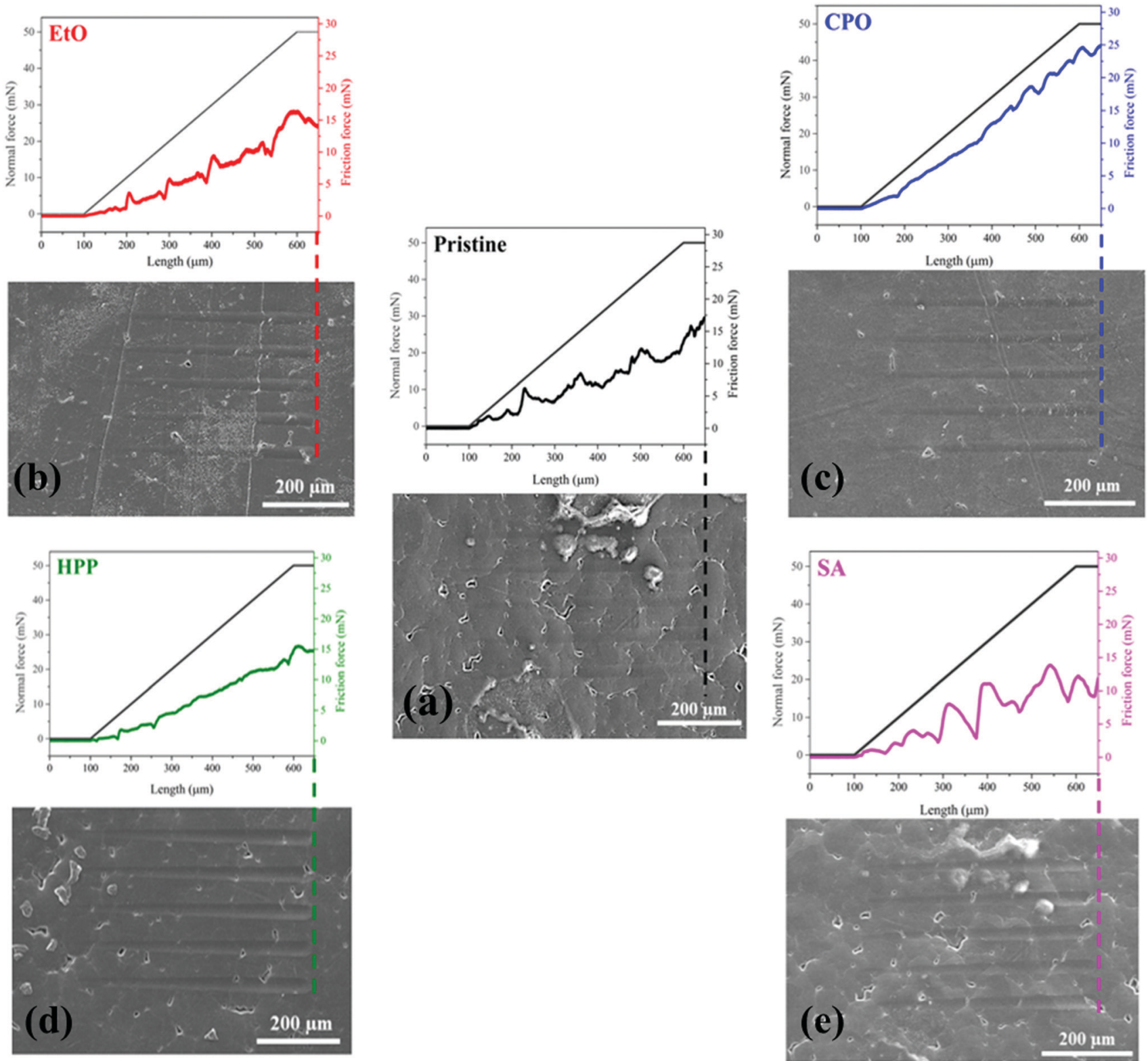

Fig. 6 Friction and plastic deformation behaviors for different treated samples where pristine is (a), EtO (b), CPO (c), HPP (d) and SA (e). 
related to the plastic deformation induced on sample surfaces. One can note that the differences among the samples are only the sterilization process, which acts basically on surface. The signal oscillation for friction force in pristine, EtO and SA samples are due to surface irregularities. The friction force behavior is quite similar among pristine, EtO, HPP, and SA samples. However, such friction force achieves the highest values for the CPO sample. By looking at the worn surfaces of all samples, the plastic deformation is also quite similar. Indeed, the width of all trails seem to be roughly the same. As above discussed, the bulk properties were not modified at all and just chemical surface properties were affected after different sterilization processes, an expected outcome for these procedures. ${ }^{55}$ Therefore, the wear behavior should be the same, as shown by the results, and oxidized organic functions $(-\mathrm{OH}$ and $=\mathrm{CO}$ ) increase the friction force in the case of the CPO sample. ${ }^{56}$ One can notice that higher friction forces should improve posterior integration to other biosystems. ${ }^{57,58}$

\subsection{Lateral force microscopy (LFM)}

Fig. 7 presents the friction force maps obtained by LFM as well as Fig. 8 present the average friction force to each PE sample. The increase in nanoscale friction force is noticeable in all sterilized samples. This indicates a surface modification tailored by the sterilization processes, which can be claimed from the replacing topography and functional groups set over the material. This nanoscale result complements the previous discussion with microwear since sterilization processes seem to change surface properties when compared to pristine condition. The graph in Fig. 8 gives a prompt remark on these features: CPO has a greater friction force in comparison to other processes, while HPP and SA are subjected to roughly the same friction force and EtO is front to an exceptionally smaller friction force. For CPO, the high friction force is in consonance

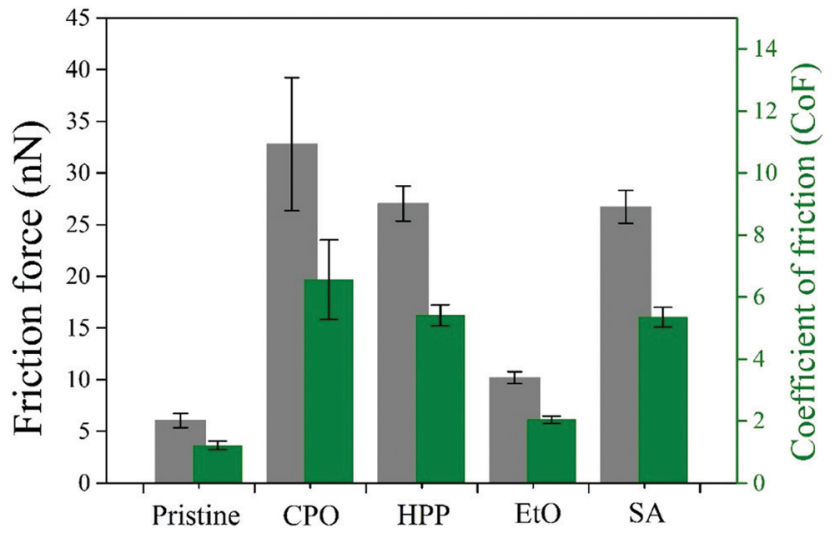

Fig. 8 Friction forces and coefficients for the studied conditions.

with previously discussed nanoscratch trails, where it displayed, by a wide margin, the greater friction force amongst all samples. This is also resonant with hydrophilic behavior of CPO and HPP samples - both submitted to glow discharges, from which these features entail. ${ }^{26}$ Moreover, the AFM topography maps for CPO, differently from all other samples, showed in Fig. 1c, and in consonance with friction maps, seemed to present a different surface pattern. This could be an additional factor to friction and hydrophilicity, ${ }^{59}$ for example, and might be result of the plasma effect during sterilization. ${ }^{39}$

\subsection{Cytotoxicity}

The cytotoxicity of the sterilized samples was evaluated by the method of converting MTT to formazan crystals through viable cells. This assay is widely used to measure the cytotoxic potential of drugs in established cell lines or in primary or secondary cultures. ${ }^{60}$ The comparative results of the cytotoxic effect of the CPO, EtO, HPP and SA samples with the negative and positive control are shown in Fig. 9.
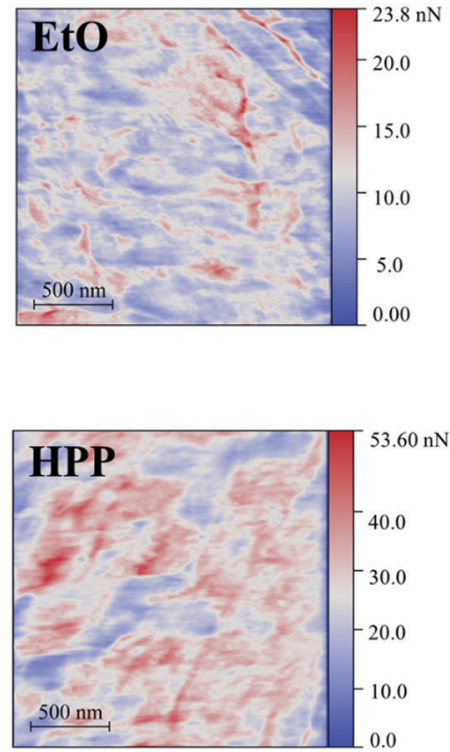
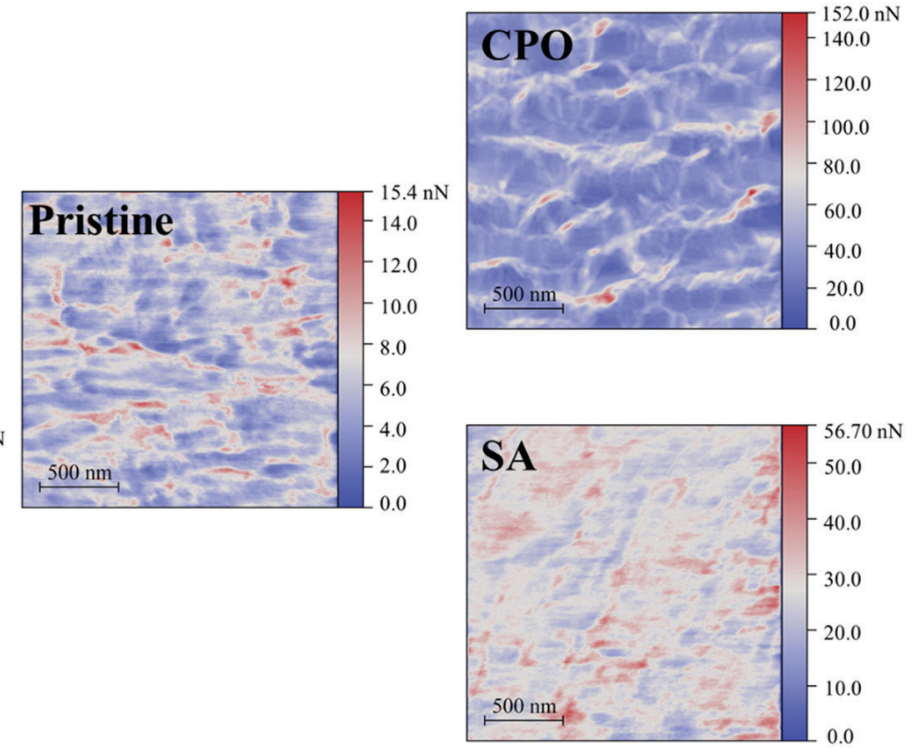

Fig. 7 LFM images displaying friction maps from scanned areas for the studied conditions. 


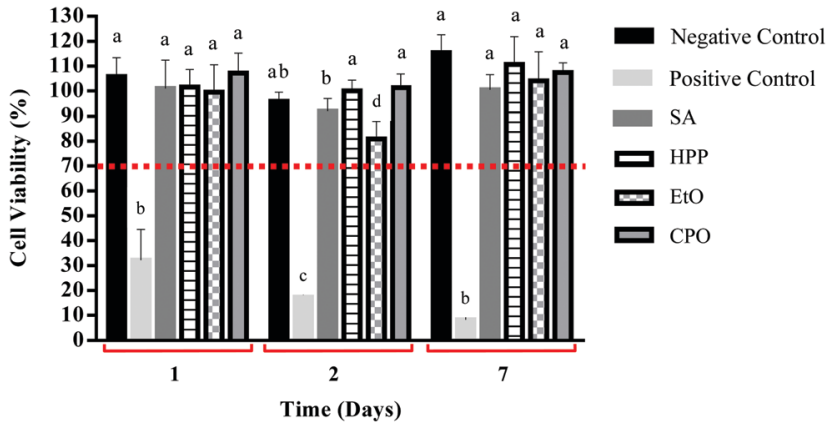

Fig. 9 Cell viability obtained by performing an indirect test according to ISO 10993-5-2009-2 of polyethylene extracts compared to negative control (DMEM medium, 10\% SFB and 1\% P/S) and positive control (DMEM medium, $10 \%$ SFB, $1 \%$ P/S and $5 \%$ dimethylsulfoxide) on the viability of treated L929 cells for 1,2 , and 7 days. Letters ( $a, b, c$ and d) correspond to the statistically significant differences - ANOVA-Tukey test $(p \leq 0.05)$. Dotted red line represents the cut off of $70 \%$ of cell viability established by ISO standards.
The data show a small decrease in cell viability of the EtO sample after two days of incubation. However, after 7 days of incubation, an increase in cell viability of this same sample was observed. When comparing the results obtained with the negative control (normalized as $100 \%$ viability), it was observed that all sterile samples did not display cytotoxicity, and are in line with the standards established by ISO 10993-12 and ISO 10993-5-2009-2, which considers a cut off of $70 \%$ for cytotoxic materials.

\subsection{Cellular adhesion and spreading}

L929 mouse fibroblasts leverage on surface topography and surface chemistry to either adhere or spread over the material (Fig. 10). ${ }^{4}$ In this set, CPO surfaces showed mostly round shaped fibroblasts, indicating poor cellular adhesion. High resolution SEM images can be viewed in Fig. A2-A5 (ESI $\dagger$ ).

\section{$1^{\text {st }}$ day}

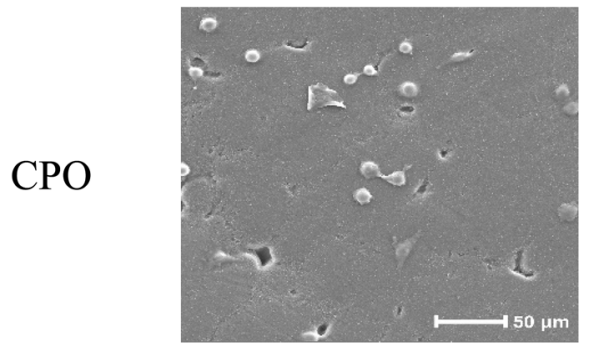

EtO
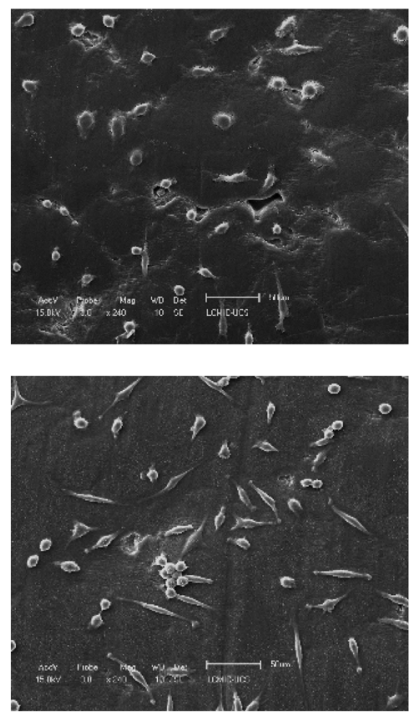

HPP

SA

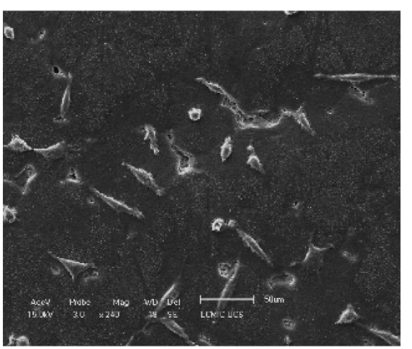

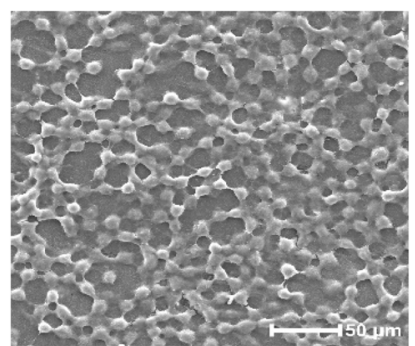
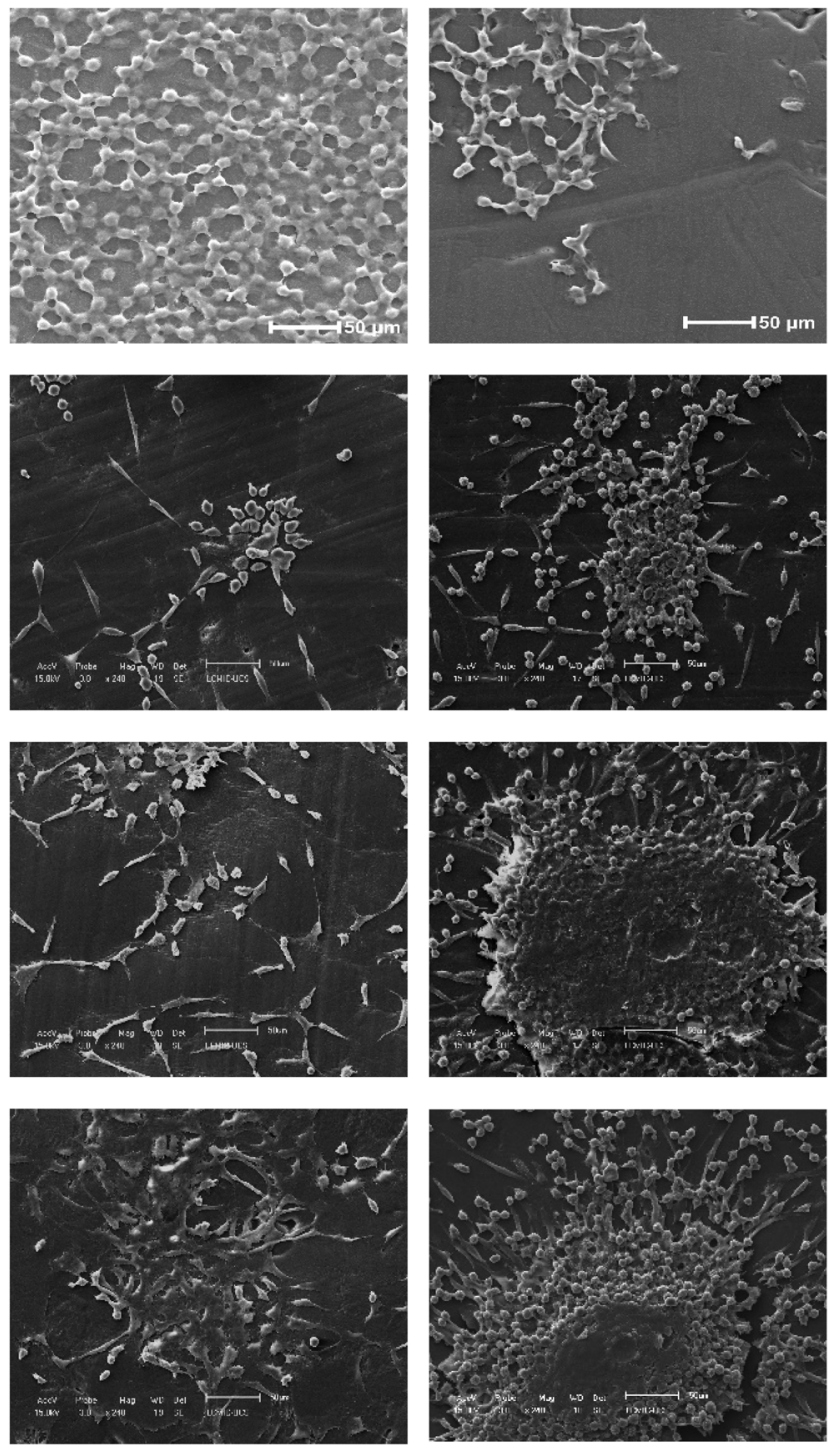

Fig. 10 Scanning electron microscopy images of CPO, EtO, HPP and SA samples after 1, 2 and 7 days of incubation. 
For most samples, cell adhesion intensified from 1st to 2nd and then to 7th day, with the exception of CPO, in which cells did not show signs of good adhesion once cytoplasm remained shrunken.

Cell adhesion is a process triggered by protein adsorption, among other features, - and wettability can be a good indicator of how adhesion will take place, as they foresee how such proteins, fibronectin and albumin, may interact with substrate.

That being said, studies have once and again discussed how hydrophilicity gives a preference pathway for cellular adhesion in different types of cells, e.g., lipophilic properties of cells may be repelled by a high surface energy. The underlying effects to be taken into account are also dependent on the application of a said workpiece. In orthopedics, much is said about a concomitant effect of enhancing osteoblast activity, while avoiding fibroblastic adhesion, ${ }^{61,62}$ the latter which may lead to myofibroblast differentiation and, therefore, unwanted fibrous response. In a nutshell, CPO has a mostly inert, like pure UHMWPE, ${ }^{18}$ surface towards L929 cells.

Overall, HPP and SA sterilized samples showed cluster of cells after a week of incubation, while CPO and EtO more disperse cell proliferation over this period. This, however, does not indicate cytotoxicity, but rather how surface chemistry is affecting cell adhesion. CPO has significant modification from incoming ultraviolet radiation - with effects on its scratch resistance, crystallinity - while the other conditions had decline in thermal stability instead. This way, different cellular adhesion and proliferation behavior is readily expected, considering that all samples were incubated using the same protocol condition.

Cold plasma oxidation is mentioned as having a long-lasting hydrophilic effect on UHMWPE, ${ }^{26}$ and this is possibly incoming from additional groups introduced into the samples' surfaces, seen in FTIR results - that could be credited as to why cell adhesion decreases over time ${ }^{26,32,63}$ a converse phenomenon observed to that on the rest of the samples. Another impacting factor would be the surface texture, especially on the micro-scale, where cell adhesion phenomena occurs - and also AFM results indicate a much rougher surface for CPO samples, leading to a hindering of L929 cell spreading. ${ }^{64}$ Overall, biocompatibility aspects were not compromised in the different treatments, once cells adapted to all conditions in a different way.

\section{Conclusion}

The investigation of sterilization in implants is an ongoing science, as each day new geometries, sizes and pre-processes are applied to UHMWPE. Along with these constraints, each patient will have its own loading over these bearing surfaces. As in recent years, conventional gamma radiation has been dropped by many manufacturers of polyethylene prosthesis, alternatives have surged such as the gas plasma and ethylene oxide.

Our study displayed a variety of possible outcomes for various antioxidant stabilizer-free sterilization processes, pointing out favorable characteristics on the developed method of cold plasma sterilization. As a surface property, friction has shown signs of improvement through nanoscratch tests in CPO samples, which means a better interaction between surfaces, while its thermal degradation behavior, a bulk property observed in TGA, remained mostly similar to pristine condition. ATR-FTIR displayed that cold plasma had the greatest effect on modifying the surfaces on the set of samples, as seen by the addition of new trans-vinylene functional groups and $\mathrm{C}=\mathrm{C}$, responsible for the long-lasting stability in wettability of these samples, which can also be inferred by the LFM results, where friction coefficient outclassed the remaining processes and cell adhesion and distribution parameters, where the lipophilic behavior of L929 cells is converse to the surface's nature.

\section{Conflicts of interest}

There are no conflicts to declare.

\section{Acknowledgements}

The authors are grateful to the following divisions at the University of Caxias do Sul (UCS): Materials Graduate Program (PPGMAT), the Biotechnology Institute (IB), and the Microscopy Center (LCMic). MMR, EKKB, CAF, and CA are CNPq fellows. CPF and LML are CAPES fellows. RF is FAPERGS/CAPES fellow. This study was financed in part by the Coordenação de Aperfeiçoamento de Pessoal de Nível Superior - Brasil (CAPES) Finance Code - 001, and INCT-INES (CNPq).

\section{References}

1 S. S. Kumar and S. S. Hiremath, Surf. Topogr.: Metrol. Prop., 2019, 7, 1-20.

2 N. J. Hallab, K. J. Bundy, K. O’Connor, R. L. Moses and J. J. Jacobs, Tissue Eng., 2001, 7, 55-70.

$3 \mathrm{~J}$. Fu, E. Oral and O. K. Muratoglu, in UHMWPE Biomaterials for Joint Implants, ed. J. Fu, ZM. Jin and J. Wang, Springer, 2019, pp. 115-150.

4 C. Meng, Y. Chen, M. Xie, Z. Yu and B. Yang, J. Biomed. Mater. Res., Part A, 2018, 106, 321-332.

5 ASTM F2625-10, ASTM Stand., DOI: 10.1520/F2625-07.2.

6 L. Costa, M. P. Luda, L. Trossarelli, E. M. Brach Del Prever, M. Crova and P. Gallinaro, Biomaterials, 1998, 19, 659-668.

7 T. J. Kinnari, J. Esteban, N. Zamora, R. Fernandez, C. LópezSantos, F. Yubero, D. Mariscal, J. A. Puertolas and E. GomezBarrena, Clin. Microbiol. Infect., 2010, 16, 1036-1041.

8 Y. H. An, F. I. Alvi, Q. Kang, M. Laberge, M. J. Drews, J. Zhang, M. A. Matthews and C. R. Arciola, Int. J. Artif. Organs, 2005, 28, 1126-1137.

9 G. Bertoli, I. M. Gindri, P. O. Cubillos, C. R. M. Roesler and G. V. Salmoria, Int. J. Adv. Des. Manuf. Technol., 2019, 101, 235-241. 
10 M. C. Tanzi, S. Farè and G. Candiani, in Foundations of Biomaterials Engineering, ed. M. C. Candiani, T. Silvia and F. Gabriele, Elsevier Ltd, 2019, pp. 289-328.

11 O. K. Muratoglu and W. H. Harris, J. Biomed. Mater. Res., 2001, 56, 584-592.

12 T. Lorson, M. Ruopp, A. Nadernezhad, J. Eiber, U. Vogel, T. Jungst and T. Lühmann, ACS Omega, 2020, 5, 6481-6486.

13 M. C. Sobieraj and C. M. Rimnac, J. Mech. Behav. Biomed. Mater., 2009, 2, 433-443.

14 S. M. Kurtz, M. L. Villarraga, M. P. Herr, J. S. Bergström, C. M. Rimnac and A. A. Edidin, Biomaterials, 2002, 23, 3681-3697.

15 S. Lerouge, A. C. Fozza, M. R. Wertheimer, R. Marchand and L. Yahia, Plasmas Polym., 2000, 5, 31-46.

16 I. A. Soloshenko, V. V. Tsiolko, V. A. Khomich, A. I. Shchedrin, A. V. Ryabtsev, V. Y. Bazhenov and I. L. Mikhno, Plasma Phys. Rep., 2000, 26, 792-800.

17 P. Fulin, D. Pokorny, M. Slouf, M. Nevoralova, T. Vackova, J. Dybal and J. Pilar, BMC Musculoskeletal Disord., 2014, 15, 1-8.

18 G. Kaklamani, N. Mehrban, J. Chen, J. Bowen, H. Dong, L. Grover and A. Stamboulis, Biomed. Mater., 2010, 5, 1-10.

19 H. Aboltakhty, A. Rashidi, M. E. Yazdanshenas and S. Shahidi, Orient. J. Chem., 2018, 34, 301-313.

20 K. N. Pandiyaraj, V. Selvarajan, R. R. Deshmukh and M. Bousmina, Surf. Coat. Technol., 2008, 202, 4218-4226.

21 C. Y. Hu and T. R. Yoon, Biomater. Res., 2018, 22, 1-12.

22 V. Sharma, S. Bose, B. Kundu, S. Bodhak, D. Mitun, V. K. Balla and B. Basu, ACS Biomater. Sci. Eng., 2020, 6, 1462-1475.

23 J. Fu, B. N. Doshi, E. Oral and O. K. Muratoglu, Polymer, 2013, 54, 199-209.

24 F. Ansari, M. D. Ries and L. Pruitt, J. Mech. Behav. Biomed. Mater., 2016, 53, 329-340.

25 P. Taddei, S. Affatato, M. Rocchi, C. Fagnano and M. Viceconti, J. Mol. Struct., 2008, 875, 254-263.

26 M. M. Rodrigues, C. P. Fontoura, C. S. C. Garcia, S. T. Martins, J. A. P. Henriques, C. A. Figueroa, M. Roesch-Ely and C. Aguzzoli, Mater. Sci. Eng., C, 2019, 102, 264-275.

27 E. K. K. Baldin, C. Garcia, J. A. P. Henriques, M. R. Ely, E. J. Birriel, R. N. Brandalise and C. D. F. Malfatti, J. Mater. Res., 2018, 33, 161-177.

28 F. Alam, M. Choosri, T. K. Gupta, K. M. Varadarajan, D. Choi and S. Kumar, Mater. Sci. Eng., B, 2019, 241, 82-91.

29 E. Gnecco, R. Pawlak, M. Kisiel, T. Glatzel and E. Meyer, in Nanotribology and Nanomechanics: An Introduction, ed. B. Bhushan, Springer, 4th edn, 2017.

30 D. Nečas and P. Klapetek, Cent. Eur. J. Phys., 2012, 10, 181-188.

31 S. E. More, J. R. Dave, P. K. Makar, S. V. Bhoraskar, S. Premkumar, G. B. Tomar and V. L. Mathe, Appl. Surf. Sci., 2020, 506, 144665.

32 A. Chaichi, A. Prasad, L. Kootta Parambil, S. Shaik, A. Hemmasian Ettefagh, V. Dasa, S. Guo, M. L. Osborn, R. Devireddy, M. M. Khonsari and M. R. Gartia, ACS Biomater. Sci. Eng., 2019, 5, 2147-2159.
33 A. J. T. Teo, A. Mishra, I. Park, Y. J. Kim, W. T. Park and Y. J. Yoon, ACS Biomater. Sci. Eng., 2016, 2, 454-472.

34 M. Shimel, I. Gouzman, E. Grossman, Z. Barkay, S. Katz, A. Bolker, N. Eliaz and R. Verker, Adv. Mater. Interfaces, 2018, 5, 1800295.

35 K. Wu, S. P. Douglas, G. Wu, A. J. MacRobert, E. Allan, C. E. Knapp and I. P. Parkin, J. Mater. Chem. B, 2019, 7, 3310-3318.

36 E. Biazar, M. Heidari, A. Asefnejad and N. Montazeri, Int. J. Nanomed., 2011, 6, 631-639.

37 S. Migita, S. Okuyama and K. Araki, J. Appl. Biomater. Funct. Mater., 2016, 14, 65-69.

38 D. P. Oliveira, A. Palmieri, F. Carinci and C. Bolfarini, Mater. Sci. Eng., C, 2015, 51, 248-255.

39 S. M. M. Spyrides, F. S. Alencastro, E. F. Guimaraes, F. L. Bastian and R. A. Simao, Surf. Coat. Technol., 2019, 378, 124990.

40 F. Lüthen, R. Lange, P. Becker, J. Rychly, U. Beck and J. G. B. Nebe, Biomaterials, 2005, 26, 2423-2440.

41 M. C. Sobieraj and C. M. Rimnac, J. Mech. Behav. Biomed. Mater., 2009, 2, 433-443.

42 S. M. Kurtz, The UHMWPE Handbook: Ultra-High Molecular Weight Polyethylene in Total Joint Replacement, 2004.

43 S. Tone, M. Hasegawa, G. Pezzotti, L. Puppulin and A. Sudo, Acta Biomater., 2017, 55, 455-465.

44 K. S. Simis, A. Bistolfi, A. Bellare and L. A. Pruitt, Biomaterials, 2006, 27, 1688-1694.

45 Y. F. Huang, J. Z. Xu, J. Y. Xu, Z. C. Zhang, B. S. Hsiao, L. Xu and Z. M. Li, J. Mater. Chem. B, 2014, 2, 971-980.

46 K. S. Kanaga Karuppiah, A. L. Bruck, S. Sundararajan, J. Wang, Z. Lin, Z. H. Xu and X. Li, Acta Biomater., 2008, 4, 1401-1410.

47 C. M. dos Santos, B. C. da Silva, E. H. Backes, L. S. Montagna, L. A. Pessan and F. R. Passador, Mater. Res., 2018, 21, 1-11.

48 J. Fu, J. Shen, G. Gao, Y. Xu, R. Hou, Y. Cong and Y. Cheng, J. Mater. Chem. B, 2013, 1, 4727-4735.

49 M. Ahmad, M. U. Wahit, M. R. A. Kadir, K. Z. M. Dahlan and M. Jawaid, J. Polym. Eng., 2013, 33, 599-614.

50 S. Sambasivan, D. A. Fischer and S. M. Hsu, J. Vac. Sci. Technol., A, 2007, 25, 932-937.

51 M. J. Martínez-Morlanes, F. J. Medel, M. D. Mariscal and J. A. Puértolas, Polym. Test., 2010, 29, 425-432.

52 L. Melk and N. Emami, Composites, Part B, 2018, 146, 20-27. 53 W. Duan, M. Wu, J. Han and Z. Ni, RSC Adv., 2020, 10, 4175-4188.

54 H. Wang, L. Xu, J. Hu, M. Wang and G. Wu, Radiat. Phys. Chem., 2015, 115, 88-96.

55 J. Horakova, M. Klicova, J. Erben, A. Klapstova, V. Novotny, L. Behalek and J. Chvojka, ACS Omega, 2020, 5, 8885-8892.

56 S. R. Bakshi, K. Balani, T. Lalia, J. Tercero and A. Agarwal, JOM, 2007, 59, 50-53.

57 S. M. Kurtz, C. M. Rimnac, L. Pruitt, C. W. Jewett, V. Goldberg and A. A. Edidin, Biomaterials, 2000, 21, 283-291.

58 A. A. Edidin, L. Pruitt, C. W. Jewett, D. J. Crane, D. Roberts and S. M. Kurtz, J. Arthroplasty, 1999, 14, 616-627. 
59 M. M. Rodrigues, C. P. Fontoura, A. E. Dotta Maddalozzo, L. M. Leidens, H. G. Quevedo, K. dos, S. Souza, J. da Silva Crespo, A. F. Michels, C. A. Figueroa and C. Aguzzoli, Composites, Part B, 2020, 189, 107909.

60 J. van Meerloo and G. J. L. K. J. Cloos, in Cancer Cell Culture: Methods and Protocols, ed. I. Cree, Humana Press, 2011, pp. 151-159.

61 A. Cohen, P. Liu-Synder, D. Storey and T. J. Webster, Nanoscale Res. Lett., 2007, 2, 385-390.
62 E. Fadeeva, S. Schlie, J. Koch and B. N. Chichkov, J. Adhes. Sci. Technol., 2010, 24, 2257-2270.

63 I. Y. Grubova, M. A. Surmeneva, V. V. Shugurov, N. N. Koval, I. I. Selezneva, S. M. Lebedev and R. A. Surmenev, J. Med. Biol. Eng., 2016, 36, 440-448.

64 T. S. Demina, M. G. Drozdova, M. Y. Yablokov, A. I. Gaidar, A. B. Gilman, D. S. Zaytseva-Zotova, E. A. Markvicheva, T. A. Akopova and A. N. ZelenetskiI, Plasma Processes Polym., 2015, 12, 710-718. 